\title{
Pharmacists' Activities to Reduce Medication Waste: An International Survey
}

\author{
Charlotte L. Bekker 1,2 (D), Helga Gardarsdottir ${ }^{2,3}$, Antoine C. G. Egberts ${ }^{2,3}$ (D), Marcel L. Bouvy ${ }^{3}$ \\ and Bart J. F. van den Bemt 1,4,5,* \\ 1 Department of Pharmacy, Sint Maartenskliniek, 6574 NA Nijmegen, The Netherlands; \\ c.bekker@maartenskliniek.nl \\ 2 Department of Clinical Pharmacy, Division Laboratories and Pharmacy, University Medical Centre Utrecht, \\ 3584 CX Utrecht, The Netherlands; h.gardarsdottir@uu.nl (H.G.); a.c.g.egberts@umcutrecht.nl (A.C.G.E.) \\ 3 Division of Pharmacoepidemiology and Clinical Pharmacology, Utrecht Institute for Pharmaceutical \\ Sciences, Utrecht University, 3584 CG Utrecht, The Netherlands; m.l.bouvy@uu.nl \\ 4 Department of Pharmacy, Radboud University Medical Centre, 6525 GA Nijmegen, The Netherlands \\ 5 Department of Clinical Pharmacy and Toxicology, Maastricht University Medical Centre, \\ 6229 HX Maastricht, The Netherlands \\ * Correspondence: b.vandenbemt@maartenskliniek.nl; Tel.: +31-24-365-9061
}

Received: 26 July 2018; Accepted: 23 August 2018; Published: 29 August 2018

\begin{abstract}
Aim: To identify activities that pharmacists undertake to reduce medication waste, and to assess the extent to which these activities are implemented, their importance for waste-reduction and feasibility for broad implementation. Methods: A two-phase survey was conducted among community and hospital pharmacists working in different developed countries. Phase one used an open-ended questionnaire to identify activities undertaken by pharmacists. Answers were thematically analysed to construct a list of medication waste-reducing activities. In phase two, a questionnaire was disseminated among pharmacists from different countries, to assess if these activities are implemented (yes/no), their importance and feasibility (1 to 5 ranking scale). Results: In phase one, 53 pharmacists participated and 14 activities were identified. These were categorized into the pharmaceutical supply chain: prescribing, dispensing (pharmacy/patient-related) and leftover stage. In phase two, 89 pharmacists participated. Most activities were implemented by a minority of pharmacists. Reducing medication amounts in stock was most frequently implemented (dispensing stage pharmacy-related; $86 \%$ ), followed by collecting unused medications (leftover stage; $77 \%$ ) and performing a medication review (dispensing stage; 68\%). Waste-reducing activities in the dispensing stage activities were both considered most important and feasible (ranked 4). Overall, most activities scored higher on importance than on feasibility. Conclusions: Pharmacists have various opportunities to reduce medication waste throughout the pharmaceutical supply chain, however, not all are broadly implemented. Pharmacists consider waste-reducing activities important, but they are less certain about the feasibility for implementation in practice.
\end{abstract}

Keywords: medication waste; unused medication; pharmacy practice; clinical pharmacy; survey research

\section{Introduction}

Medication waste can occur in all stages of the pharmaceutical supply chain. For instance, physicians may prescribe unnecessarily large quantities (prescribing stage). During the dispensing stage, pharmacists dispense larger quantities as manufacturers' package sizes may exceed the amount required for treatment. Once medication has been supplied to the patient, early treatment changes, 
for example, due to some side effects or unsatisfactorily efficacy, can lead to an excessive amount of unused medication at home. Moreover, low adherence of patients to treatment regimens can contribute to medication waste as well. Finally, medications that are left unused and of good quality, are generally destroyed if returned to the pharmacy [1-5].

There is increased awareness of the financial impact of medication waste [6-9]. Health care budgets are limited and unused medications can be considered a waste of resources. It is important that patients dispose of these properly, for instance, by returning these to pharmacies or chemical waste depots. However, patients sometimes incorrectly dispose of unused medications through household garbage, the toilet, or sink, with the risk of polluting the environment [10]. Active pharmaceutical ingredients have been detected in surface, ground, and drinking water $[11,12]$ that may have detrimental effects on aquatic species and ecosystems [13,14]. Efforts to reduce medication waste and the undesirable economic and environmental burden are, therefore, warranted.

Pharmacists are key players in the pharmaceutical supply chain and are in a position to contribute to the reduction of medication waste [15]. One can presume that individual pharmacists have already initiated various strategies to reduce this waste. However, information about activities that are implemented in practice to reduce waste is limited. The availability of such information could facilitate an exchange of knowledge between pharmacists on how to reduce medication waste and could promote the implementation of such activities in daily practice. Therefore, the aim of this study was to identify activities that individual pharmacists have currently undertaken in community and hospital pharmacies in developed countries to reduce medication waste. Moreover, this study aimed to assess the extent to which these activities are implemented, the importance of the activities for reducing waste, and the feasibility for broadly implementing these activities in daily practice.

\section{Materials and Methods}

\subsection{Study Design}

This survey consisted of two phases: an exploratory phase of which the results were used for the subsequent assessment phase. The study was conducted between July 2014 and October 2016. The first phase aimed to identify activities currently undertaken by individual pharmacists and the second phase aimed to assess the extent to which these activities are implemented and their importance and feasibility (see Figure 1 for overview). 


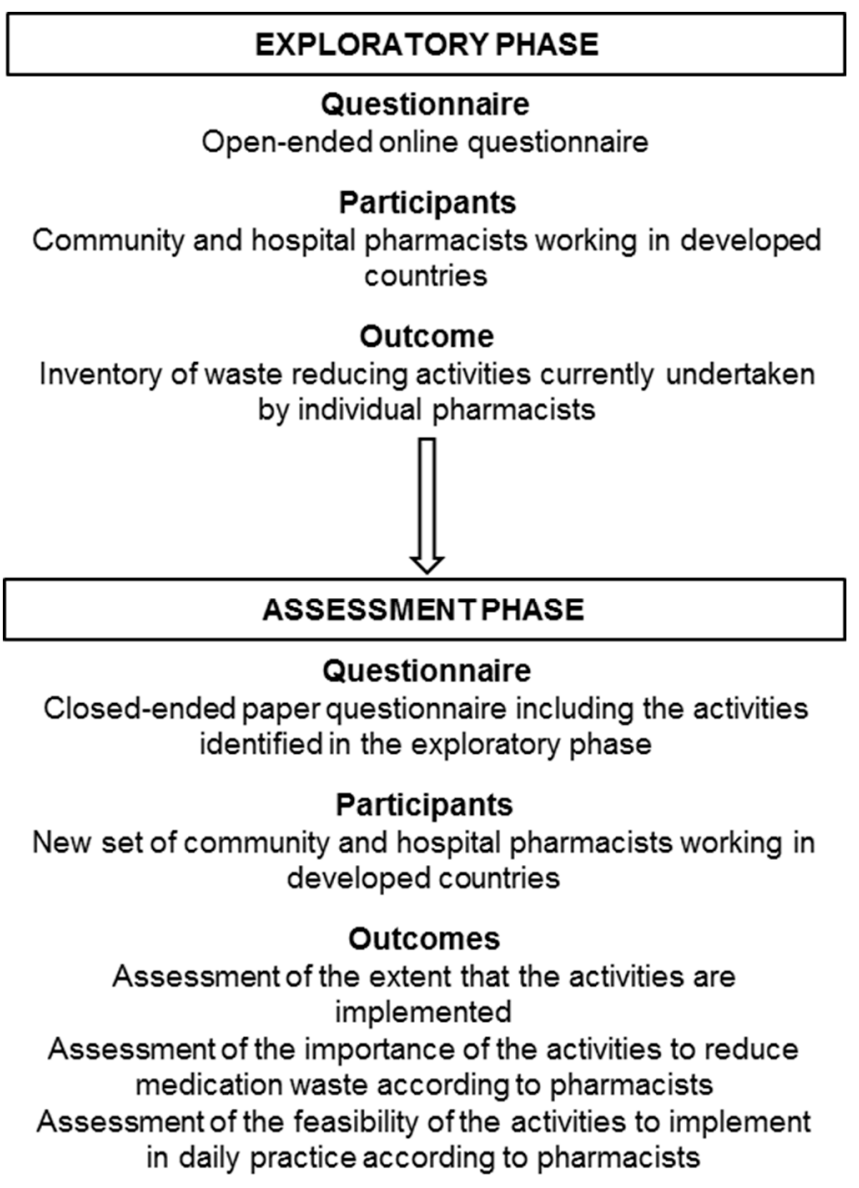

Figure 1. Overview of the main methods used for the two phases.

\subsection{Ethics}

All data were analysed anonymously. Under Dutch law, no approval from an Ethical Review Board was required as only health care professionals were involved.

\subsection{Phase One: Exploration}

\subsubsection{Participants' Inclusion and Data Collection}

Pharmacists working in a community, hospital or academic setting located in a country with a ranking of 'very high' on the human development index [16] were eligible for participation. Pharmacists were approached through (inter)national organizations of pharmacists or through the personal network of the research group. Pharmacists received an email invitation explaining the purpose of the study that included a link to the questionnaire. Non-responders received two reminders, the first reminder was sent two weeks after the initial invitation and the second two weeks thereafter. Countries were only included in the analysis if two pharmacists from that country completely filled in the questionnaire.

\subsubsection{Questionnaire}

Activities that individual pharmacists have implemented to reduce medication waste were explored by an open-ended questionnaire that was created in an online survey tool. The questionnaire was developed by the research group and pre-tested in terms of interpretation by a pharmacist who was not involved in the study. The questionnaire consisted of three sections (see Appendix A): the prescribing, the dispensing and the leftover stage. Each section consisted of several questions that 
focused on activities implemented to reduce medication waste. As the community and hospital setting may differ, hospital pharmacists were asked two additional questions regarding activities implemented during the (preparation prior to) administration of medications and activities implemented at the hospitals' wards. Pharmacists' country of origin and work setting (community pharmacy/hospital pharmacy/academic) were recorded as well.

\subsubsection{Data Analysis}

Data from the questionnaires were exported to Microsoft Excel version 2010 (Microsoft, Albuquerque, NM, USA) and analysed using thematic content analysis [17]. Pharmacists' answers were coded by the first researcher and reviewed by the second researcher [18]. Any disagreements between the two researchers were discussed until consensus was reached. Hereafter, both researchers independently categorized the activities into the three previous defined stages according to their content which they subsequently discussed until both agreed.

\subsection{Phase Two: Assessment of Implementation, Importance and Feasibility}

\subsubsection{Participants' Inclusion and Data Collection}

A questionnaire was constructed based on the results of the first phase. This questionnaire was distributed among pharmacists participating in the 45th European Symposium on Clinical Pharmacy that was held in Oslo, Norway, in October 2016. Only questionnaires completed by pharmacists working in a country, as defined in phase one, were included in the analysis.

\subsubsection{Questionnaire}

Questions were formulated for all activities that were identified during the first phase of the study and divided into the predefined stages (Appendix B). The questionnaire was also pre-tested by a pharmacist not involved in the research study. For each activity, pharmacists were asked to indicate whether the activity was implemented in their country (yes/no), to rank the importance of the activity to reduce waste and the feasibility to implement in practice. Answers were measured on a scale with a range from one, denoting the activity as not important or feasible, to five, very important or feasible. In addition, pharmacists were able to add other activities if these were not included. Their country of origin and work setting (community pharmacy/hospital pharmacy/academic/other) were recorded as well.

\subsubsection{Data Analysis}

Data from the questionnaires were imported in Microsoft Excel and descriptively analysed (frequencies and percentages). To equally weigh the frequency scores, more than $50 \%$ of the pharmacists within a country should have reported implementing the activity, because activities taken by fewer than half of the pharmacists within a country were assumed to be taken at random and therefore not counted. The importance and feasibility ranking scales were assessed as medians with interquartile ranges. First, the median ranking for each activity within each country was determined. Subsequently, the median ranking for all activities were calculated and averaged per stage. All analyses were performed in STATA version 13 (StataCorp, College Station, TX, USA) and Microsoft Excel.

\section{Results}

Fifty-three pharmacists from 19 developed countries were included in the first phase of the study (Appendix C). The activities currently undertaken by individual pharmacists to reduce medication waste were categorized into the prescribing, dispensing and leftover stage. During the analysis, two subthemes within the dispensing stage were added, i.e., activities related to the pharmacy or to the patient's medication therapy and storage practices. In total, 14 main activities were identified (Table 1). 
Eighty-nine pharmacists from 22 developed countries were included in the second phase (Appendix D). The pharmacists reported no new activities on top of the activities that were identified in phase one. Results of the two phases are presented together per stage hereafter to facilitate a comprehensive presentation.

Table 1. Waste-reducing activities that can be undertaken by pharmacists and their estimated frequency of activities implemented to reduce medication waste. A country was considered to have implemented an activity if more than $50 \%$ of the pharmacists within that country reported that the activity is implemented.

\begin{tabular}{lc}
\hline \multicolumn{1}{c}{ Activity } & $\begin{array}{c}\text { Countries } \\
(\mathbf{n}=\mathbf{2 2}) \mathbf{n}(\mathbf{\%})\end{array}$ \\
\hline The prescribing stage & $7(31.8)$ \\
\hline Prescribers tailor prescription amounts & $7(31.8)$ \\
\hline Counsel prescribers on efficient prescribing & \\
\hline The dispensing stage & $10(45.5)$ \\
\hline Pharmacy related & $11(50.0)$ \\
\hline Pharmacists adjust prescribed amounts & $12(54.5)$ \\
\hline Dispense opened medication package & $19(86.4)$ \\
\hline Use dose-dispensing system & $18(94.7)$ \\
\hline Manage medication amounts in stock & $14(73.7)$ \\
\hline Limiting storage amounts & $7(31.8)$ \\
\hline Exchange medications with other pharmacies & \\
\hline Pooling patients & $2(9.1)$ \\
\hline Stient related & $15(68.2)$ \\
\hline Review patient's medications & $5(22.7)$ \\
\hline Discuss needed quantity & $10(45.5)$ \\
\hline Use home medications during hospitalization & $17(77.3)$ \\
\hline The leftover stage & $4(18.2)$ \\
\hline Collect unused medications & $0(0)$ \\
\hline Donate unused medications & \\
\hline Redispense unused medications & \\
\hline
\end{tabular}

\subsection{The Prescribing Stage}

To reduce medication waste in the prescribing stage, two main activities that were undertaken were identified. Namely, prescribers could tailor the prescribed amount and pharmacists could counsel prescribers on the prescribed amount. Most pharmacists mentioned that prescribers tailor the amount based on medication characteristics (e.g., cost), on patient characteristics (e.g., age) and the expected duration of time until symptoms should resolve. Some pharmacists remarked that they counsel prescribers on how to prevent waste. For instance, by recommending the duration of use for each prescription whenever possible.

Activities in the prescribing stage were reported to be implemented by approximately one-third of the countries (Table 1). On average, these activities were considered important for reducing waste (median ranking 4), and were ranked neutral in terms of the feasibility of their implementation in practice (median ranking 3, Figures 2 and 3). 


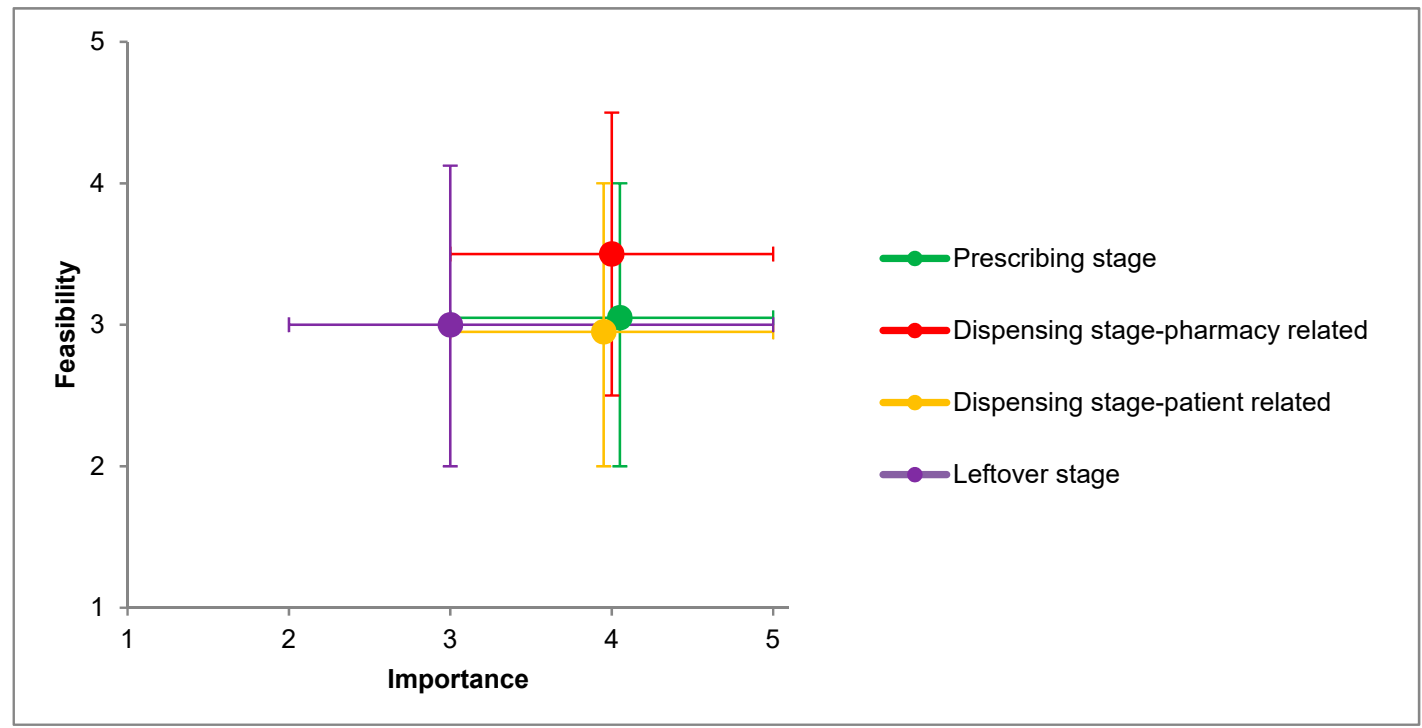

Figure 2. For each stage of the pharmaceutical supply chain, median importance ranking to reduce medication waste and median feasibility ranking to implement in practice (with upper and lower quartile) given by the pharmacists.

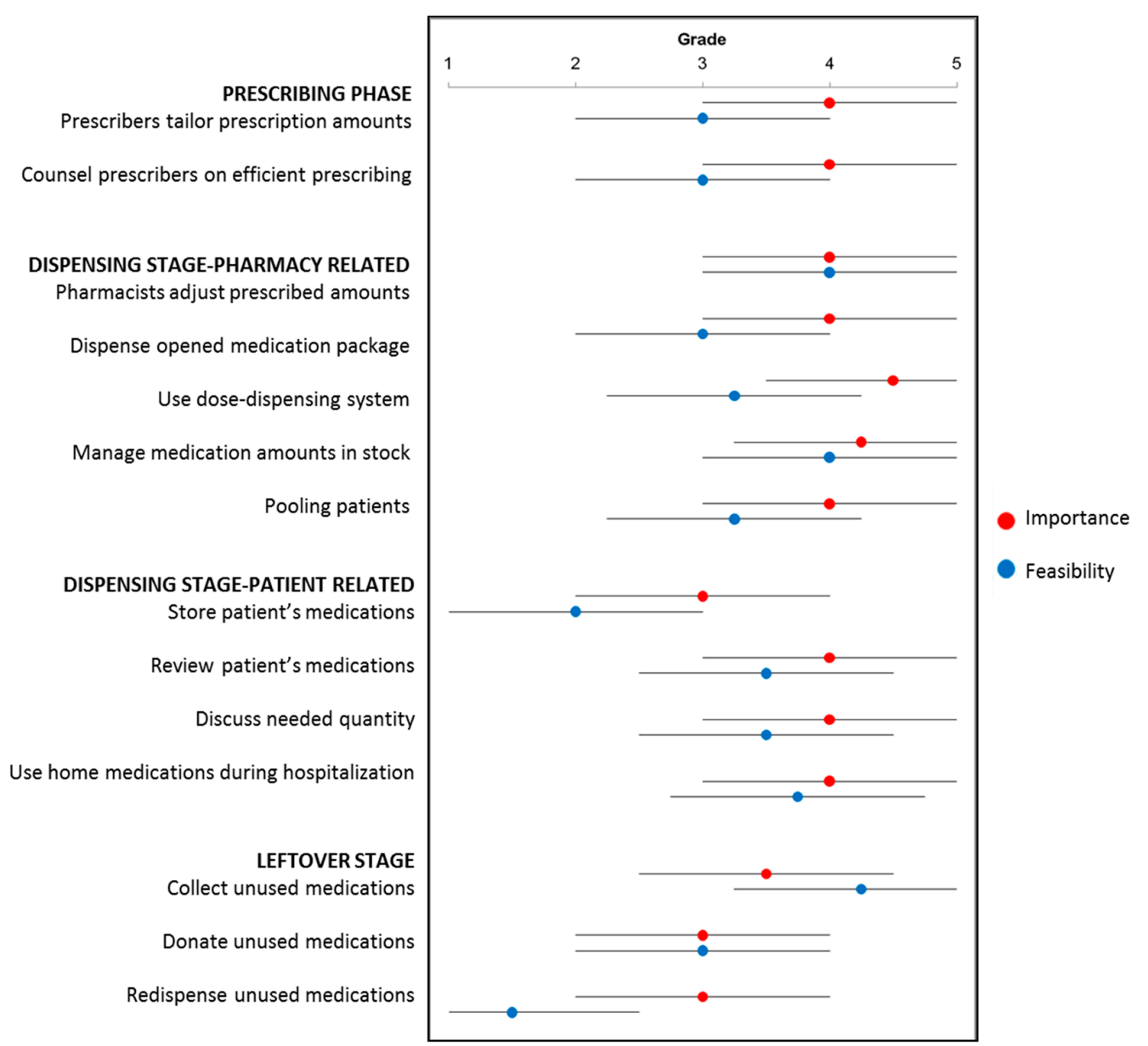

Figure 3. For each activity, median importance ranking to reduce medication waste and median feasibility ranking to implement in practice (with upper and lower quartile) given by the pharmacists. 


\subsection{The Dispensing Stage}

\subsubsection{Pharmacy Related Activities}

Activities undertaken by pharmacists to reduce medication waste in the dispensing phase focused mainly on dispensing smaller amounts to the patient, by adjusting the amount of prescribed medications to the treatment duration, dispensing opened medication packages and using dose-dispensing systems. Most pharmacists indicated that the number of days for which medications can be dispensed is limited by law and generally concerns a three-month supply. Some pharmacists mentioned that they are allowed to adjust the amount of medications prescribed without consulting the prescriber. One example of such an activity is when a pharmacist notices that a physician has prescribed more than needed, they inform the patient and reduce the dispensed amount. However, this approach is not achievable for all pharmacists as it was frequently reported that pharmacists are only allowed to dispense complete medication packages, even when the prescribed amount is less. Concerning internal waste management at the pharmacy, pharmacists mentioned that they manage the amount of medications kept in stock. For example, some pharmacies exchange medications that are rarely used or that are close to the expiry date to prevent disposal. In some hospital pharmacies, patients who are treated with parenteral medications are scheduled on the same day in order to pool injection vials.

Stock management was most frequently reported activity implemented to reduce medication waste, in $86.4 \%$ of the responding countries. Of these countries, $94.7 \%$ indicated that they limit the amount of medications that are kept in stock and $73.7 \%$ collaborated with other pharmacies to exchange medications. The other pharmacy-related activities of the dispensing stage were reported to be implemented by approximately half of the countries. The activities were ranked the highest in terms of importance and feasibility. Of all activities, using dose-dispensing systems and stock management ranked highest concerning their importance for reducing waste (median ranking $>4$ ), but lower on feasibility for implementation (median ranking 3 and 4 respectively).

\subsubsection{Patient-Related Activities}

Patient-related activities for reducing waste reported in the dispensing stage aimed at optimizing medication therapy and storage management by the patient. These include storing the majority of patient's medications at the pharmacy, reviewing the patient's medications, and starting a dialogue with the patient about the quantity needed. Furthermore, through discussion with the patient, pharmacists try to adjust the dispensed amount to the patient's actual needs, and to increase their awareness about waste. Some hospital pharmacists reported that patients are allowed to use their own home medications during hospital admission, thereby reducing medication waste.

Sixty-eight percent of the responding countries reported to perform medication reviews. Only 9.1\% of the countries stored patients' medications at the pharmacy and this was considered less feasible (median ranking 2). Overall, patient-related activities in the dispensing stage were considered important for reducing waste (median ranking 4), but scored lower on feasibility for implementation (median ranking 3).

\subsection{The Leftover Stage}

Three waste-reducing activities were identified in the leftover stage. Community and hospital pharmacists mentioned that the amount of unused medications is collected in the pharmacy for safe disposal. A few pharmacists indicated that these medications are donated to charities for people in need. As a last activity, hospital pharmacists mentioned that unused medications were redispensed, under the condition that the medications were stored at the hospital ward and had not been dispensed to patients.

Of the responding countries, $77.3 \%$ reported collecting unused medications and $18.2 \%$ donating unused medications. None of the countries reported redispensing unused medications returned by 
patients. Activities aimed at tackling medication waste during the leftover stage scored lowest in terms of both importance and feasibility (median rankings 3).

\section{Discussion}

This study shows that pharmacists undertake several activities to limit medication waste in all stages of the pharmaceutical supply chain. More than half of the participating countries reported using dose-dispensing systems, managing the amount of medication in stock, performing medication reviews, and collecting unused medications. Pharmacists considered activities of the prescribing and dispensing stage most important for reducing medication waste and pharmacy-related activities of the dispensing stage most feasible for implementation in practice. Most activities scored lower in terms of feasibility than importance.

This is the first study that gives an overview of activities taken by community and hospital pharmacists. For this study, several limitations could be identified. Most importantly, only pharmacists were consulted. It is possible that other healthcare professionals would identify other medication waste-reducing activities. Also, not all pharmacists of the countries approached responded to the survey, hence, some activities might have been missed. However, no additional activities were mentioned in the second phase of the study that included other countries as well. Therefore, one can assume that the list of potential activities to reduce waste is comprehensive. Third, the second researcher was not blinded for the coding of the first researcher. However, the pharmacists mentioned concrete activities and thus the risk of misclassification is considered minimal. Fourth, not all questionnaires were fully completed. We found that the reported answers of uncompleted questionnaires did not differ from the fully completed questionnaires. Hence, it is assumed that the missing answers would not have altered the findings. Fifth, the respondents and the activities they reported might not necessarily be representative for their whole country. However, it still enabled us to report on activities that pharmacists have implemented to reduce medication waste and to indicate which activities are implemented most frequently. Sixth, only activities implemented by the majority of pharmacists within a country were considered to be implemented by that country. This could have resulted in an underestimation of the frequency that activities were taken. Finally, this study involved pharmacists working in developed countries, and any generalization of our results with respect to other countries should be viewed with caution.

Many pharmacists considered the waste-reducing activities as important, which emphasizes the necessity for interventions that aim to combat medication waste. The study suggests that activities that are related to the organization of the pharmacy and the dispensing stage were most often implemented and were considered most feasible. Overall, activities that focus on waste prevention were found to be most promising. But as not all activities were considered achievable to implement in practice, this may suggest that barriers hamper feasible implementation and a need for feasible waste-reducing interventions. Looking at the current evidence of potential interventions, an example of a waste-reducing activity in the prescribing stage is to dispense smaller amounts of expensive medications. Limiting the amount of medication supplied for a first time to a two-week period, followed by 30 days for a repeat prescription [19], may decrease the risk of unused medications and unnecessary waste. Patients receiving medications for more than 30 days are more likely to waste a part of those medications [20,21]. Additionally, pharmacists could also supply a trial prescription amount to the patient at the start of treatment and supply the remainder when the medication is well tolerated. Paterson et al. showed that a split-fill supply could reduce the cost of medication waste [22]. Regarding the dispensing stage, studies show that increasing the frequency of medication batch preparations or scheduling patients with the same therapy on the same day in the hospital pharmacy could reduce medication waste and expenditures [23-25]. However, applying such strategies in the community pharmacy is not financially feasible as large quantities of relatively low-cost medications are generally dispensed and additional dispensing fees may outweigh the savings on medication costs [26]. Pharmacists should, therefore, consider the individual medication costs when deciding if 
smaller amounts should be dispensed to the patient, as this may not always save costs, however, it might still reduce the risk of environmental pollution.

It is important not to focus on waste reduction by prescribers and pharmacists but also to increase patients' awareness of medication waste. Patients often only pay a part of the medication cost out of pocket and are not always aware of the total cost of medication. Governments and health care authorities have started campaigns to raise patients' awareness about medication prices, including displaying the price on the medication package or on the dosage label [27]. Furthermore, discussing the quantity dispensed with the patient could reduce the supply of unwanted medications and, potentially, medication waste [28]. If adherence of patients to their treatment regimen could be increased, medication waste might be reduced as well. Moreover, medication reviews could be periodically conducted to identify medication therapies that are dispensed to patients but no longer needed or non-adherence. Unnecessary medication therapies could thereby be discontinued helping to reduce the waste of unnecessary healthcare costs. Regarding the leftover stage, very few interventions have been investigated and most studies assess the amount and economic value of medications returned to pharmacies [2,4,29-31]. The donation of medications to other countries is disapproved of by the World Health Organization [32]. The question as to whether medications returned to pharmacies could be redispensed remains hypothetical $[33,34]$, as many prerequisites need to be addressed in order to redispense unused medications, such as how to ascertain the quality of the medications, the patients trust in redispensed medications, and the legal- and financial feasibility $[35,36]$.

Multiple interventions seem promising for reducing medication waste. However, it seems that various barriers hamper their implementation. Barriers one could think of are each nation's reimbursement systems which influence how medications are prescribed, dispensed and collected at the pharmacy. Furthermore, legislation could be challenging to the implementation of waste-reducing activities. Some of the respondents reported that different activities, such as splitting packages into smaller quantities, are not legally allowed. Even within a country, pharmacists can counteract waste differently as this will also depend on the availability of resources in the pharmacy, like sufficient knowledge of pharmacy workers of the possibilities to reduce medication waste and the monetary budget. For the successful implementation of waste-reducing interventions, such barriers should be identified and overcome first.

\section{Conclusions}

This study demonstrates that pharmacists have developed many activities to reduce medication waste in all stages of the pharmaceutical supply chain. However, not all potential activities to reduce medication waste have been implemented in daily practice. Activities focusing on waste prevention seem most promising. Even though pharmacists consider activities for reducing medication waste important, they are less certain about the feasibility of broadly implementing these activities in daily clinical practice.

Author Contributions: Conceptualization, C.L.B., H.G., A.C.G.E., M.L.B. and B.J.F.v.d.B.; Data curation, C.L.B., H.G., A.C.G.E., M.L.B. and B.J.F.v.d.B.; Formal analysis, C.L.B.; Investigation, C.L.B., H.G., A.C.G.E., M.L.B. and B.J.F.v.d.B.; Project administration, C.L.B.; Supervision, H.G., A.C.G.E., M.L.B. and B.J.F.v.d.B.; Writing-original draft, C.L.B.; Writing—review and editing, H.G., A.C.G.E., M.L.B. and B.J.F.v.d.B.

Funding: This research received no external funding.

Acknowledgments: The authors want to thank all pharmacists who participated in this study. Special thanks go out to Aya Al-Rashed who performed the data collection of the exploratory phase.

Conflicts of Interest: The authors declare no conflict of interest.

\section{Appendix A. Questionnaire of Phase One}

1. Which initiatives are taken nationally and in pharmacies to minimize medication waste?

- Initiatives taken by prescribers. 
- Initiatives taken in the pharmacy during dispensing.

- Initiatives taken for leftover unused medications.

Prescribing stage

2. Which phases are taken by prescribers to minimize medication waste?

3. In which cases is the number of drugs prescribed tailored on a patient's health condition?

4. In which cases is the number of drugs prescribed tailored on costs or on other drug characteristics?

Dispensing stage

5. Which initiatives are taken in pharmacies during the dispensing of medications?

6. What is the maximum amount of days for which medications can be dispensed in your country?

7. Which initiatives are taken at the different departments of the hospital?

8. Which initiatives are taken in the hospital pharmacy while preparing/compounding the medication?

Leftover stage

9. What is done with unused medications that are returned to the pharmacy?

Appendix B. Questionnaire of Phase Two

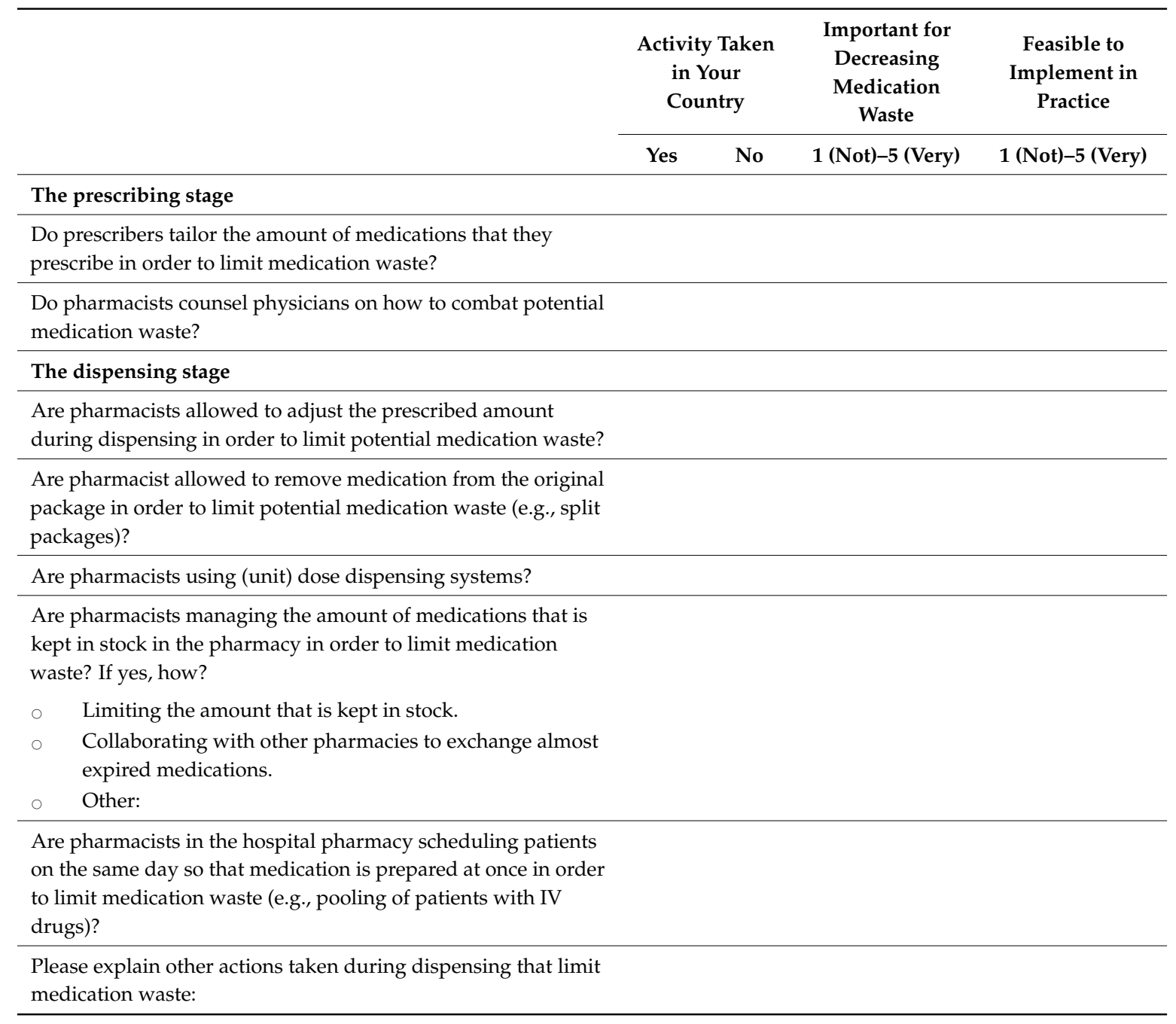




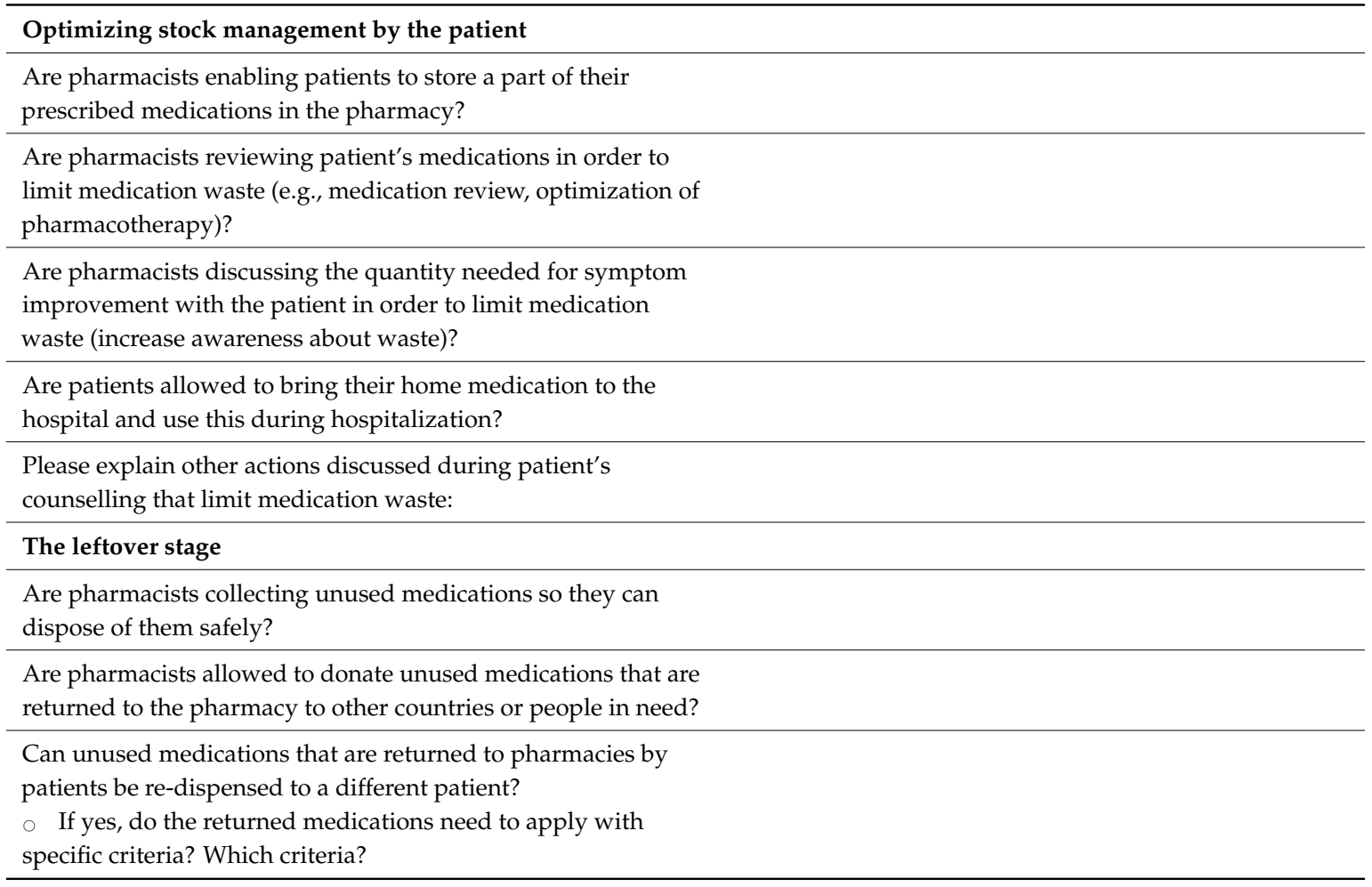

Appendix C. Number of Pharmacists per Country of Origin and Work Setting that Participated in Phase One

\begin{tabular}{cccc}
\hline $\mathbf{n}=\mathbf{1 9}$ & Total $\mathbf{n}=\mathbf{5 3}$ & $\begin{array}{c}\text { Community Pharmacy } \\
\mathbf{n}=\mathbf{3 9}\end{array}$ & $\begin{array}{c}\text { Hospital Pharmacy } \\
\mathbf{n}=\mathbf{1 4}\end{array}$ \\
\hline Australia & 2 & 2 & \\
Belgium & 4 & 3 & 1 \\
Canada & 2 & 2 & \\
Croatia & 2 & 2 & 1 \\
Denmark & 3 & 2 & 1 \\
Estonia & 5 & 4 & 1 \\
Finland & 2 & 1 & 1 \\
France & 2 & 1 & 1 \\
Iceland & 8 & 8 & 2 \\
Ireland & 2 & 1 & 1 \\
Italy & 2 & & 1 \\
Malta & 2 & 1 & 1 \\
Netherlands & 4 & 3 & 1 \\
New Zealand & 2 & 1 & \\
Norway & 2 & 1 & 1 \\
Spain & 2 & 2 & 1 \\
Switzerland & 3 & 2 & \\
United Kingdom & 2 & 2 & \\
United States & 2 & 1 & \\
\hline
\end{tabular}


Appendix D. Number of Pharmacists per Country of Origin and Work Setting That Participated in Phase Two. 12 Pharmacists Were Working in Multiple Settings and therefore the Total Sum Exceeds 89

\begin{tabular}{|c|c|c|c|c|c|}
\hline $\mathrm{n}=\mathbf{2 2}$ & Total $n=89$ & $\begin{array}{l}\text { Community Pharmacy } \\
\qquad n=13\end{array}$ & $\begin{array}{l}\text { Hospital Pharmacy } \\
\qquad n=66\end{array}$ & $\begin{array}{c}\text { Academic } \\
\mathrm{n}=15\end{array}$ & Other $n=7$ \\
\hline Australia & 1 & & 1 & & \\
\hline Austria & 11 & & 11 & 1 & \\
\hline Belgium & 2 & & 2 & & \\
\hline Canada & 2 & 2 & & 1 & \\
\hline Croatia & 1 & 1 & & & \\
\hline Denmark & 1 & 1 & & 1 & \\
\hline Estonia & 2 & & 2 & & \\
\hline Finland & 1 & & & & 1 \\
\hline France & 6 & & 6 & 2 & \\
\hline Germany & 2 & 2 & & 1 & \\
\hline Ireland & 1 & & & 1 & \\
\hline Italy & 2 & & 2 & & \\
\hline Netherlands & 5 & 2 & 1 & 1 & 1 \\
\hline Norway & 24 & & 21 & 2 & 1 \\
\hline Portugal & 4 & 1 & 2 & 1 & 1 \\
\hline Romania & 2 & & 2 & & \\
\hline Slovakia & 1 & & 1 & & \\
\hline Slovenia & 4 & & 3 & 1 & \\
\hline
\end{tabular}

\section{References}

1. Braund, R.; Gn, G.; Matthews, R. Investigating unused medications in New Zealand. Pharm. World Sci. 2009, 31, 664-669. [CrossRef] [PubMed]

2. Coma, A.; Modamio, P.; Lastra, C.F.; Bouvy, M.L.; Mariño, E.L. Returned medicines in community pharmacies of Barcelona, Spain. Pharm. World Sci. 2008, 30, 272-277. [CrossRef] [PubMed]

3. Ekedahl, A.B.E. Reasons why medicines are returned to Swedish pharmacies unused. Pharm. World Sci. 2006, 28, 352-358. [CrossRef] [PubMed]

4. Langley, C.; Marriott, J.; Mackridge, A.; Daniszewski, R. An analysis of returned medicines in primary care. Pharm. World Sci. 2005, 27, 296-299. [CrossRef] [PubMed]

5. Law, A.V.; Sakharkar, P.; Zargarzadeh, A.; Tai, B.W.B.; Hess, K.; Hata, M.; Mireles, R.; Ha, C.; Park, T.J. Taking stock of medication wastage: Unused medications in US households. Res. Soc. Adm. Pharm. 2015, 11, 571-578. [CrossRef] [PubMed]

6. Bach, P.B.; Conti, R.M.; Muller, R.J.; Schnorr, G.C.; Saltz, L.B. Overspending driven by oversized single dose vials of cancer drug. BMJ 2016, 352, i788. [CrossRef] [PubMed]

7. Trueman, P.; Lowson, K.; Blighe, A.; Meszaros, A.; Wright, D.; Glanville, J. Evaluation of the Scale, Causes and Costs of Waste Medicines; YHEC/School of Pharmacy, University of London: London, UK, 2010.

8. Wasserfallen, J.; Bourgeois, R.; Büla, C.; Yersin, B.; Buclin, T. Composition and Cost of Drugs Stored at Home by Elderly Patients. Ann. Pharmacother. 2003, 37, 731-737. [CrossRef] [PubMed]

9. Bekker, C.L.; Melis, E.J.; Egberts, A.C.G.; Bouvy, M.L.; Gardarsdottir, H.; Van Den Bemt, B.J.F. Quantity and economic value of unused oral anti-cancer and biological disease-modifying anti-rheumatic drugs among outpatient pharmacy patients who discontinue therapy. Res. Soc. Adm. Pharm. 2018. [CrossRef] [PubMed]

10. Kusturica, M.; Tomas, A.; Sabo, A. Diposal of unused drugs: Knowledge and behaviour among people around the world. Rev. Environ. Contam. Toxicol. 2017, 240, 71-104.

11. Kolpin, D.; Furlong, E.; Meyer, M.; Michael Thurman, E.; Zaugg, S.; Barber, L.; Buxton, H. Pharmaceuticals, hormones, and other organic wastewater contaminants in U.S. streams, 1999-2000: A national reconnaissance. Environ. Sci. Technol. 2002, 36, 1202-1211. [CrossRef] [PubMed] 
12. Mompelat, S.; Le Bot, B.; Thomas, O. Occurrence and fate of pharmaceutical products and by-products, from resource to drinking water. Environ. Int. 2009, 35, 803-814. [CrossRef] [PubMed]

13. Jobling, S.; Williams, R.; Johnson, A.; Taylor, A.; Gross-Sorokin, M.; Nolan, M.; Tyler, C.R.; Van Aerle, R.; Santos, E.; Brighty, G. Predicted exposures to steroid estrogens in U.K. rivers correlate with widespread sexual disruption in wild fish populations. Environ. Health Perspect. 2006, 114, 32-39. [CrossRef] [PubMed]

14. Niemuth, N.J.; Jordan, R.; Crago, J.; Blanksma, C.; Johnson, R.; Klaper, R.D. Metformin exposure at environmentally relevant concentrations causes potential endocrine disruption in adult male fish. Environ. Toxicol. Chem. 2015, 34, 291-296. [CrossRef] [PubMed]

15. FIP (International Pharmaceutical Federation). Green Pharmacy Practice: Taking Responsibility for the Environmental Impact of Medicines; International Pharmaceutical Federation: The Hague, The Netherlands, 2015.

16. United Nations Development Programme. Human Development Report 2014 Sustaining Human Progress: Reducing Vulnerability and Building Resilience; United Nations Development Programme: New York, NY, USA, 2014.

17. Braun, V.; Clarke, V. Using thematic analysis in psychology. Qual. Res. Psychol. 2006, 3, 77-101. [CrossRef]

18. Boeije, H. Analysis in Qualitative Research, Think and Do; Boom Lemma Uitgevers: Den Haag, The Netherlands, 2014. (In Dutch)

19. Ministry of Health Welfare and Sports. Arrangement: Preventing Waste by Limited Prescribing. Available online: https:/ / www.rijksoverheid.nl/ministeries/ministerie-van-volksgezondheid-welzijn-ensport/nieuws/2016/11/29/afspraak-verspilling-voorkomen-door-korter-voorschrijven (accessed on 12 December 2016).

20. Maeng, D.D.; Ann, L.; Wright, E.A. Patient characteristics and healthcare utilization patterns associated with unused medications among medicare patients. Res. Soc. Adm. Pharm. 2016, 13, 1090-1094. [CrossRef] [PubMed]

21. Bekker, C.L.; Van Den Bemt, B.J.F.; Egberts, A.C.G.; Bouvy, M.L.; Gardarsdottir, H. Patient and medication factors associated with preventable medication waste and possibilities for redispensing. Int. J. Clin. Pharm. 2018, 40, 704-711. [CrossRef] [PubMed]

22. Paterson, J.M.; Anderson, G.M. "Trial" prescriptions to reduce drug wastage: Results from Canadian programs and a community demonstration project. Am. J. Manag. Care 2002, 8, 151-158. [PubMed]

23. Fasola, G.; Aprile, G.; Marini, L.; Follador, A.; Mansutti, M.; Miscoria, M. Drug waste minimization as an effective strategy of cost-containment in Oncology. BMC Health Serv. Res. 2014, 14, 57. [CrossRef] [PubMed]

24. Toerper, M.F.; Veltri, M.A.; Hamrock, E.; Mollenkopf, N.L.; Holt, K.; Levin, S. Medication waste reduction in pediatric pharmacy batch processes. J. Pediatr. Pharmacol. Ther. 2014, 19, 111-117. [CrossRef] [PubMed]

25. Tilson, V.; Dobson, G.; Haas, C.E.; Tilson, D. Mathematical modeling to reduce waste of compounded sterile products in hospital pharmacies. Hosp. Pharm. 2014, 49, 616-627. [CrossRef] [PubMed]

26. Millar, J.; McNamee, P.; Heaney, D.; Selvaraj, S.; Bond, C.; Lindsay, S.; Morton, M. Does a system of instalment dispensing for newly prescribed medicines save NHS costs? Results from a feasibility study. Fam. Pract. 2009, 26, 163-168. [CrossRef] [PubMed]

27. Torjesen, I. Costs of some drugs will be displayed on packs to try to reduce waste and improve adherence. BMJ 2015, 351, h3637. [CrossRef] [PubMed]

28. Jesson, J.; Business, A.; Pocock, R. Reducing medicines waste in the community. Prim. Health Care Res. Dev. 2005, 6, 117-124. [CrossRef]

29. James, T.H.; Helms, M.L.; Braund, R. Analysis of Medications Returned to Community Pharmacies. Ann. Pharmacother. 2009, 43, 1631-1635. [CrossRef] [PubMed]

30. Guirguis, K. Medications collected for disposal by outreach pharmacists in Australia. Pharm. World Sci. 2010, 32, 52-58. [CrossRef] [PubMed]

31. Mackridge, A.J.; Marriott, J.F. Returned medicines: Waste or a wasted opportunity? J. Public Health 2007, 29, 258-262. [CrossRef] [PubMed]

32. WHO (Would Health Organization). Guidelines for Medicine Donations, 3rd ed.; World Health Organization: Geneva, Switzerland, 2011.

33. Lenzer, J. US could recycle 10 million unused prescription drugs a year, report says. BMJ 2014, 349, g7677. [CrossRef] [PubMed]

34. Pomerantz, J. Recycling Expensive Medication: Why Not? Medscape Gen. Med. 2004, 6, 4. 
35. Bekker, C.L.; Gardarsdottir, H.; Egberts, T.C.G.; Bouvy, M.L.; van den Bemt, B.J.F. Redispensing of medicines unused by patients: A qualitative study among stakeholders. Int. J. Clin. Pharm. 2017, 39, 196-204. [CrossRef] [PubMed]

36. Mcrae, D.; Allman, M.; James, D. The redistribution of medicines: Could it become a reality? Int. J. Pharm. Pract. 2016, 24, 411-418. [CrossRef] [PubMed] 